\title{
Modular milling cutter with inner-cooling network
}

\author{
Mircea-Viorel Dragoi ${ }^{1,}{ }^{*}$, Dorin Mircea Rosca $^{1}$, Milena Flavia Folea ${ }^{1}$, and Gheorghe Oancea ${ }^{1}$ \\ ${ }^{1}$ Transilvania University of Braşov, Department of Manufacturing Engineering, Eroilor 29, Brasov, \\ 500036, Romania
}

\begin{abstract}
The big sized milling cutters are expensive tools and are not appropriate for small batches production. Making these tools more versatile, able to fit to different kinds of processes and shapes of the parts to be machined is a must. As well, cooling the cutting area is very important. The existing end-mill cutters are designed to feed internally with coolant only the teeth on the front side. The paper presents a concept of a modular tool, made of elementary disk cutters, able to be reconfigured to get different shapes and sizes. The main element of novelty the paper claims is the inner cooling system of the complex tool. The special design of the elementary milling cutters and of the shaft they are mounted on make the tool able to lead jets of coolant to every insert, no matter where they are placed, on the cylindrical or on the front side of the milling cutter. A network of channels drilled in the shaft and in the body of elementary milling cutters make this possible. The capability to splash with coolant under high pressure all the cutting edges do not depend on the number of teeth of the tool. Being delivered from inside the cutting tool, the coolant splashes directly on the contact surface between the inserts and workpiece, which makes cooling more efficient.
\end{abstract}

\section{Introduction}

Cooling is a key-point in cutting processes. It plays an important role in reducing cutting tool wear, prevents part dilatation, which causes a lack in dimensional precision, and may contribute to chip forming, detaching it from the part, and removing it from the cutting area. Special cooling methods and means are studied by scientists. Their research are focused to different directions: new coolant with high cooling capacity, dry cooling, and delivering coolant to cutting area by spraying it, minimum quantity lubrication, and others. A brief survey of the literature reveals some studies and achievements of the research on the subject of cooling applied to machining, as follows.

Some studies were carried on the influence of cooling on the quality of machined surface [1], and an alternative way to remove the chips from cutting area in the special case of milling composite materials [2]. Some different methods of cooling the part and tool when machining (milling) metals are discussed as well, namely electrostatic atomization lubrication [3], electrostatic spraying [4], and cryogenic cooling [5]. Dry cooling is the

* Corresponding author: dragoi.m@unitbv.ro 
method that uses only air jets for cooling the cutting area. A model of heat distribution in the cutting area is presented, and the benefits such a model can offer are emphasized [6]. A special machining is micro milling: the collision force of the classic cooling jet might be as big, so it affects the cutting tool that is very slender. In such case, alternative cooling methods are needed, e. g. the hybrid ones [7], or atomization [8]. An intensive studied subject is that of minimum quantity lubrication (MQL) [9-13]. In essence it is about using special means and methods of delivering coolant, so the cooling good performance is obtained even using a reduced quantity of coolant. However, MQL has in turn, some disadvantages, as well, revealed in [3]. Another aspect approached in the studies is the negative impact on health and on the environment of the mineral oils used as lubricant, and the need to find alternative cooling fluids (e.g. the biological originated ones) $[14,15]$. Some solutions are proposed in the cited papers: a yeast-based solution, and vegetable oil, respectively. An alternative cooling system is the inner one. It brings the coolant to the cutting area through the cutting tool itself. A comparative study between the cutting forces occurred at zig-zag milling with inner and outer cooling system has been carried [16]. Inner cooling system was studied for different machining operations: milling $[17,18]$ and grinding [19]. In [20] are presented some researches on the influence of inner cooling on wearing of the cutting tool. An optimisation of cooling was tried for multijet system: three different jets of coolant are sent towards the cutting area. One has a fixed direction, and the other two are variable. The angle of these two jets is determined to get the best cooling [21]. The present paper deals, as well, with multijet cooling system, but from a different, original perspective. The particularity of the cooling system presented here consists of that the coolant jets come from inside the cutting tool, and there is a jet for every insert. These two features make the proposed system very effective since all the cutting area is splashed with coolant, regardless the shape of the part to be machined, or the number of inserts engaged in the workpiece.

\section{A new concept of inner cooling system}

Authors of the paper have dealt for a long time with modular milling cutter, and they already have some achievements in this domain: they have published some scientific papers $[22,23]$ and issued some patent proposals [24,25]. The results described in the paper represent an enhancement of those presented in [26] and were materialized in a patent proposal [25]. The main novelty in [24] consisted of a particularly shaped shaft, able to increase the capacity to transmit torque to the elementary cutters, which have, as well, specially shaped reaming. The modular cutting tool had a new cooling system, an outer one, able to distribute the coolant along the entire surface of the complex cutting tool. The paper presents a modified modular milling cutter: the outer cooling system was turned into an inner one, with clearly brings some advantages.

\section{Results}

The new inner cooling system consists in fact of some channels drilled in the shaft and in the modular cutters. The rigorous positioning of the elementary cutters on the shaft ensure the strict correspondence of the holes in the shaft to those in the elementary disks, so all the channels form a continuous network from the source of the coolant to the neighborhood of each insert. In Figure 1(a) is presented the shaft and the holes drilled in it [25]. Figure 1(b) shows a $3 \mathrm{D}$ view of the shaft with the chamber of coolant and the channels emphasized in red colour. 


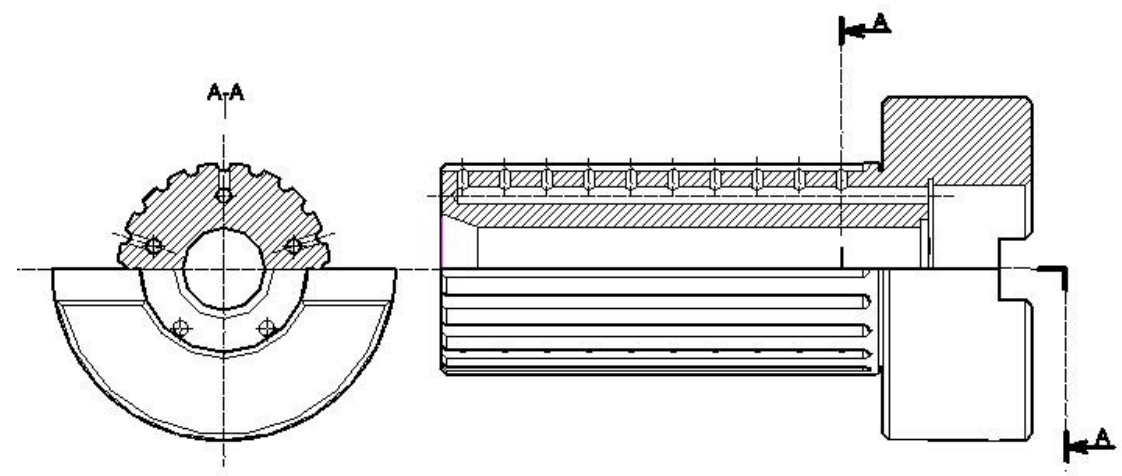

(a)

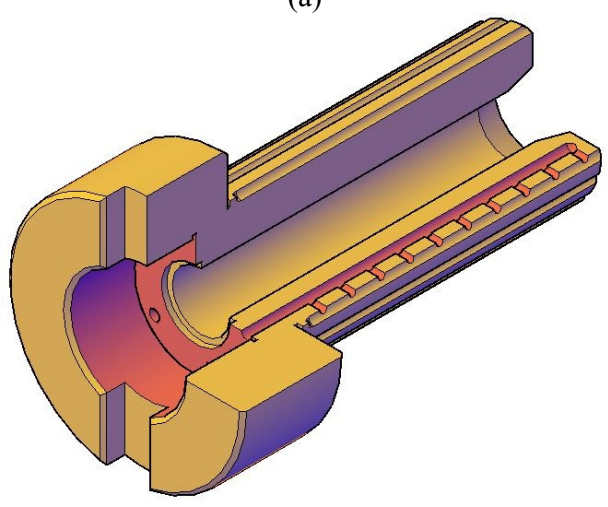

(b)

Fig. 1. Shaft with channels drilled axially and radially. (a) section and views: (b) 3Dview [25].

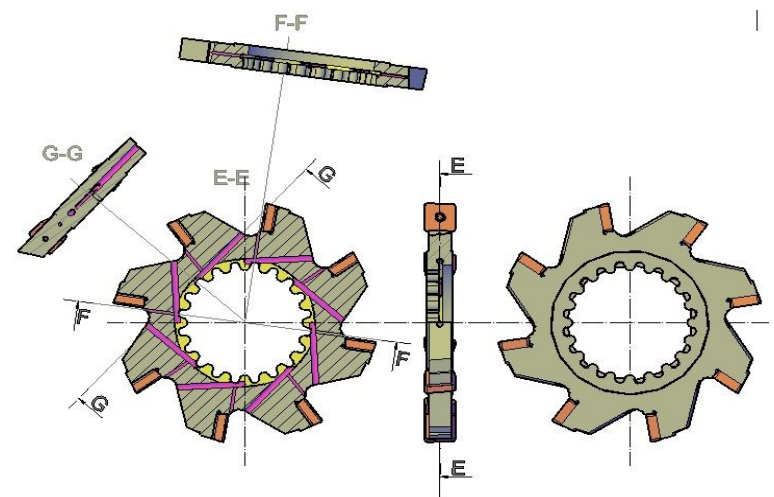

(a)

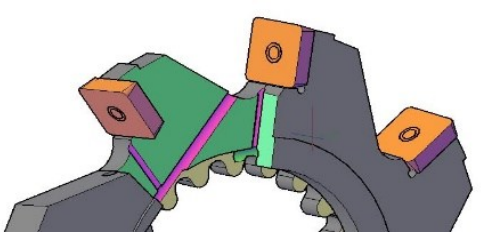

(b)

Fig. 2. Elementary milling cutter with its particular shaped reaming, and the holes that lead the coolant to the inserts. (a) 2D views and sections; (b) 3D section [25].

The coolant is delivered by the inner cooling system of the machine tool to the main room in the cutting tool shank. From here it is spread through the axial and radial channels in the shaft to the elementary milling cutters. In the body of the elementary milling cutters are drilled some holes that lead the jets of coolant to the inserts. These holes are highlighted in magenta in Figure 2(a), and 2(b). As well, some particular sections through an elementary milling cutter show more details about the network inside it. It is crucial the 
correct axially positioning the elementary cutters on the shaft, to ensure the correspondence of the holes in the shaft and the radial groove that divides the reaming of the cutters into two sections - the profiled and the smooth ones. This groove, yellow in Figure 2(a), is an intermediary passage of the coolant between the holes in shaft and in cutter. The correct axial position of the cutters is given by the distance between the holes in shaft and the strictly controlled width of the elementary disks. To every tooth of the elementary milling cutter corresponds two channels, which lead the jets to the insert along two different directions. This ensures providing with coolant both the insert, and the machined surface.

An assembled milling cutter with inner cooling network is presented in Figure 3.

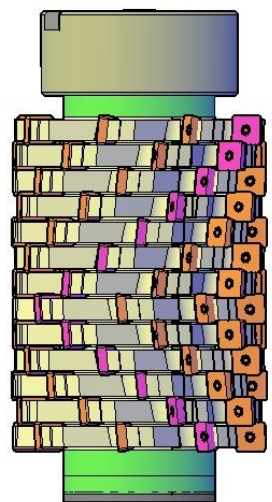

(a)

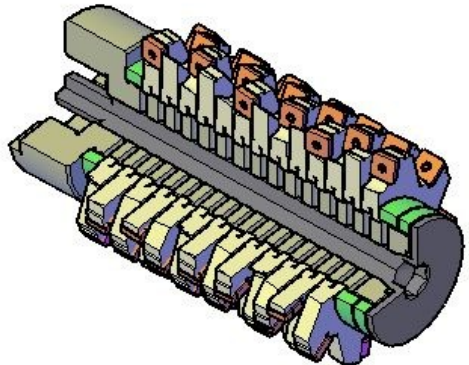

(b)

Fig. 3. Assembled milling cutter. (a) side view: (b) 3Dsection.[25]

In Figure 3(a) can be seen that depending on the way the elementary cutters are mounted on the shaft, the general direction of the side cutting edges can be controlled -left in the lower half, and right in the upper half [26]. In Figure 3(b) the section through the ensemble reveals both the channels in shaft and in elementary milling cutter. In the same picture are shown the central screw, which being screwed in the tool-holder, keeps by means of its flange, all the parts together.

Even if the edge length of the insert is bigger than the width of the body of the elementary milling cutter, this does not pose any problem in mounting the adjacent elements: the inserts extent over the width of the body, take space in the gap between the teeth of the next elements, due to their rotated position.

Some seals complete the set of parts. Their role is to prevent wasting the coolant through the gaps between adjacent parts, and force it to flow along the channels network towards the inserts and cutting area.

\section{Discussion}

The modular milling cutter with inner cooling network keeps all the advantages of the previous version, that with outer cooling system [26]. Additionally, it brings the benefits of inner cooling system. This is an original solution that belongs to the authors of the paper, and was the subject of a patent proposal [25]. The solution proposed was thought both in terms of a correct working of the modular cutting tool in the machining process, and from the perspective of manufacturing the elements of the modular cutting tool. The profile of the grooves on the shaft and on the reaming of the elementary cutting tools were designed respecting the conditions for avoiding undercuts, and to be easily manufactured, using common means - cutting tools and machine tools. The channels in the shaft and in the body of the elementary milling cutters were designed taking into account the technological 
aspects posed by the length of some holes, and of the direction of the channels. Even if network of channels is a very complex shaped one, it is proved that it is a continuous one, able to lead the coolant from the common source to every insert of the cutting tool. For sure, the network can be subject of improvement, and optimization, which concerns with the following aspects: reducing the hydraulic loss at the sudden change of the flow direction; checking, and if needed modifying the diameter of some holes to ensure a constant speed of the coolant along the entire its route from the source to the exit from the body of the elementary cutters.

The inner network of the complex cutting tool is shown in Figure 4.

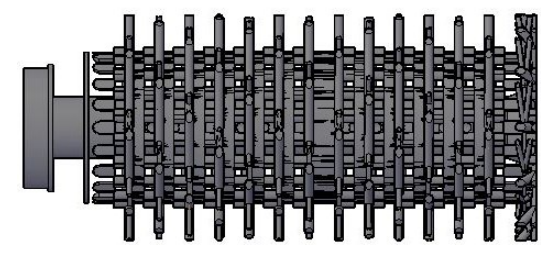

(a)

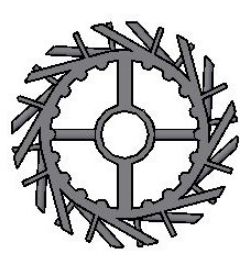

(1)

Fig. 4. Inner cooling network. (a) 2D side and front view; (b) 3D view.

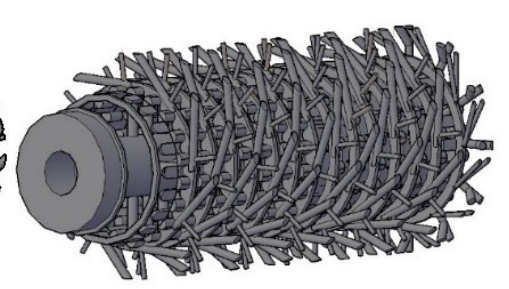

(b)

The inner cooling network has, some limitations and disadvantages, as well. In this regard, should be mentioned: the big amount of coolant spent, the system is difficult to apply to classic milling cutter, it fits well mainly for modular milling cutters; the need to ensure the correspondence between the radial holes in the shaft and the radial groove in the hole of elementary cutters - this restrictions the possibility to mount milling cutters having different widths on the shaft.

\section{Conclusion}

The proposed inner cooling system is an original one. No any other inner cooling system for milling cutters, which is able to send jets of coolant to the inserts on the side of the tool is mentioned in literature. The main advantage it brings is that can cool the closed cutting area between the cutting tool and the workpiece, which is inaccessible for other cooling systems. Even if some difficulties might occur, the system can be extended to be applied for other type of cutting tools. One can appreciate that the benefits of the new solution brings overcome its disadvantages. The new concept of modular milling cutter with inner cooling system fits better for the big sized tools, which are used in machining that suppose a large contact area between the tool and workpiece, and when the amount of chips to be removed is big.

\section{Future developments}

As have mentioned before, the modular milling cutter with inner cooling system displays some limitations and disadvantages. Future research and developments are foreseen to reduce them, or even to eliminate it. A shaft manufactured by additive technologies could benefit from curved channels, instead of the perpendicular ones, so the loss of hydraulic energy could be reduced. As well, radial holes having an elongated section instead of circular, could extend the possibility to mount on the same shaft elementary cutters having different width if needed (mainly for the profiled ones, the so-called profiled gang cutters).

The most important improvement the complex tool could benefit from, is a CFD analysis able to determine the diameter of the successive holes, so to ensure a constant 
speed of the flow along its entire path from the source to the exit from the body of the elementary cutters.

\section{References}

1. B. Chirita, N.C. Tampu, G. Brabie, M.C. Radu, IOP Conf. Ser. Mater. Sci. Eng. 145 022006 (2016)

2. Y. Liu, S Li, H. Li, X. Qin, Y. Xing, H. Liu, Int. J. Adv. Manuf. Technol. 108, 1297 (2020)

3. Y. Su, Q. Lu, T. Yu, Z. Liu, C. Zhang, Int. J. Adv. Manuf. Technol. 104, 2773 (2019)

4. Y. Su, H. Jiang, Z. Liu, Int J Adv Manuf Technol 110, 1305 (2020)

5. F. Wang, Y. Wang, Int J. Adv Manuf Technol.106, 5277 (2020)

6. G. M. Perri, M. Bräunig, G. Di Gironimo, M. Putz, A. Tarallo, V. Wittstock, Int J Adv Manuf Technol 86, 1853 (2016)

7. K. Aslantas, A. Çicek, İ. Ucun, M. Percin, H.E. Hopa, Procedia CIRP 46, 492 (2016)

8. S. E. Nevala, V. T. Wifvat, S. A. Johnson, J. E. Wentz, Proceedings of the ASME 2012 International Mechanical Engineering Congress and Exposition, Volume 3: Design, Materials and Manufacturing, Parts A, B, and C, Houston, Texas, USA, 1979 (2012)

9. G. Singh, V. Aggarwal, S. Singh, A. Kumar, Advances in Production and Industrial Engineering (Eds. Singapore: Springer Singapore, 2021)

10. A. De Bartolomeis, A. Shokrani, J. Manuf. Mater. Process. 4, 70 (2020)

11. A. Shokrani, J. Betts, CIRP Ann. 69, 73 (2020)

12. F. Günan, T. Kıvak, Ç.V. Yıldırım, M. Sarıkaya M., J. Mater. Res. Technol. 9, 10386 (2020)

13. J.K. Ho, C.H. Tsai, M.Y. Tsai, M.X. Tu, J.C. Sung, J. Chin, Inst. Eng. 38, 322 (2015)

14. O. Damm, M. Bezuidenhout, E. Uheida, L. Dicks, W. Hadasha, D. Hagedorn-Hansen, CIRP J. Manuf. Sci. Technol., S1755581721000043 (2021)

15. P. Quitiaquez, F. Calle, J. Valencia, W. Quitiaquez, 2020 IEEE ANDESCON, Quito, Ecuador, 1 (2020)

16. U. Riaz, C. Liu, G. Tan, G. Li, N. Yin, M. J. Saeed, J. Phys.: Conf. Ser. 1187, 032056 (2019)

17. L. Wen, G. Li, N. Yin, G. Tan, Advances in Mechanical Design, ICMD 2017. Mechanisms and Machine Science (Springer, Singapore, 55, 2018)

18. Y. H. Liao, Y. Wang, L. D. Zhang, Appl. Mech. Mater 496-500, 1189 (2014)

19. T. Minton, S. Ghani, F. Sammler, R. Bateman, P. Fürstmann, M. Roeder, Int. J. Mach. Tools Manuf. 75, 27 (2013)

20. N. Yin, G. Li, G. Tan, C. Shen, J. Xue, J. Phys. Conf. Ser., 1064, 012061 (2018)

21. P. Krishnan G, S. P, D. Samuel Raj, S. Hussain, V. Ravi Shankar, N. Raj, J. Manuf. Process. 64, 392 (2021)

22. D. M. Roșca, A New Constructive Conception on Cutting Tools Used for Lathing Shaped Surfaces. In Proceedings of the 1st International Conference on Computing and Solutions in Manufacturing Engineering, Brasov, Romania, 16-18 September 2004; pp. 161-163.

23. D. M. Roșca, The Functional Flexibility through the Modularisation of Cutting Tool Construction. In Proceedings of the 1st International Conference on Computing and Solutions in Manufacturing Engineering, Brasov, Romania, 16-18 September 2004; pp. $163-165$.

24. D. M. Rosca, M. F. Folea, Grooved Shaft for Positioning and Driving in Rotational Movement of Reamed Milling Cutters Elements (Translated from Romanian-Arbore Canelat Pentru Poziționarea și Antrenarea în Mișcarea de Rotaţie a Componentelor Frezelor cu Alezaj). Patent Proposal RO 130751 A0, 2017

25. D. M. Rosca, G. Oancea, M. V. Drăgoi, M. F. Folea,. Modular Mill and Gang Mill Constructions with Adjustable Dimensional and Geometric Parameters and Interior 
Cooling System in Double Version. Patent Proposal RO 132084 (A0), 30 October 2020.

26. M. V. Dragoi, D. M. Rosca, M. F. Folea, Oancea, G. A Fully Symmetrical High Performance Modular Milling Cutter. Symmetry 2021, 13, 496. 